\title{
A Systematic Review of Hospital Efficiency and Productivity Studies: Lessons from Australia, UK and Canada.
}

Bonnie Eklom ( $\square$ bonnie.eklom@my.jcu.edu.au )

James Cook University

Emily Callander

Monash University

\section{Research Article}

Keywords: Efficiency, productivity, health systems, Australia

Posted Date: December 15th, 2020

DOl: https://doi.org/10.21203/rs.3.rs-123445/v1

License: (c) (1) This work is licensed under a Creative Commons Attribution 4.0 International License.

Read Full License 


\section{Abstract}

\section{Background}

Ageing populations, more expensive technology, growing rates of chronic disease and increasing consumer expectations are expected to lead to increased demand for health services and a rise in health expenditure within Australia. Productivity and efficiency analysis of Australia's health system could provide valuable insight into the performance of the health system and assist stakeholders to reduce unnecessary growth in public hospital expenditure. This review describes efficiency and productivity analyses of hospitals in Australia, Canada and the United Kingdom.

\section{Methods}

We conducted a systematic literature review of efficiency and productivity analyses of hospitals in Australia, Canada and the United Kingdom. The search was conducted in two stages; (1) a search of the grey literature using a Google search engine; and (2) a traditional systematic review method search of academic databases. It is uncommon for grey literature to have abstracts, therefore, executive summaries, table of contents or subheadings were screened. Titles and Abstracts of journal articles were screened.

\section{Discussion}

Within Australia and key comparator nations, the number of efficiency and analysis studies is small. There is no clear consensus on the most suitable analysis technique to measure efficiency and productivity of hospitals. However, selection of inputs is similar across all studies identified in this review, consisting of measures of labour (most commonly relating to full time equivalent employees), goods and services (e.g. purchased consumables, such as drugs), and capital. Similarly, the majority of studies struggled to identify output measures that could capture improvements in patient outcomes, a key performance measure for any hospital. Instead, most studies utilised proxy measures relating to hospital throughputs (number of separations) or population health measurements. Of note, only one study demonstrated active engagement with the health sector in study development.

\section{Conclusion}

There is considerable scope for the further development of efficiency and productivity analysis techniques that can adequately capture relevant production factors, allow for robust comparisons across hospitals and time periods and which meaningfully engage with the health sector to inform improvements in efficiency and productivity.

\section{Background}

Australia has a universal health care system that provides high quality care and is often ranked among the best in the world across a number of indicators $(1,2)$. In the coming years, an ageing population, 
more expensive technology and growing rates of chronic disease are expected to lead to increased demand for health services and a consequent rise in expenditure (3). This expected increase in health expenditure is likely to be particularly evident in the public hospital sector, with public hospitals the largest area of recurrent health expenditure in Australia. In 2015-2016 State, Territory and Commonwealth expenditure on public hospital services was $\$ 51.1$ billion, a real growth of $4.4 \%$ from 2014-2015 and consistent with the average annual real growth over the decade. There are growing concerns that this rise in public hospital expenditure is unsustainable (4). Productivity and efficiency analysis of Australia's health system could provide valuable insight into the performance of the health system and assist relevant stakeholders to arrest further unnecessary growth in public hospital expenditure.

Productivity and efficiency analyses measure the performance of 'firms' (whether these be factories or hospitals). Although often used interchangeably, productivity and efficiency are distinct (but related) terms. Productivity is defined as the ratio of outputs to inputs for a given firm and can be represented by a production frontier, with input on the $(x)$ axis and output on the $(y)$ axis. Larger values of the ratio of outputs to inputs are associated with better performance or productivity (5).

In his 1957 paper, Farrell provided seminal definitions of efficiency. Technical efficiency is defined as the production of the maximum amount of output from a given amount of input (or alternatively the production of a given output with minimum input quantities) given current technology. When a firm is 'technically efficient', it operates on the production possibilities frontier (PPF), (6) which is identified from the best performing firms. As such, efficiency has a comparative element, whereby firms are compared with an optimal production situation (the PPF). Allocative efficiency is similar to technical efficiency but places a cost on inputs or outputs. Allocative efficiency is defined as the input mix that minimizes cost, given input prices or when the output mix maximizes revenue, given output prices. Together, technical and allocative efficiency comprise overall economic efficiency.

As the number of inputs and outputs of a firm increases, measurement of its efficiency and productivity becomes increasingly complex. There are a number of approaches to measuring efficiency in hospitals, which have been utilized in Australia and internationally. These include least square econometric production models, total factor productivity (TFP) indices, data envelopment analysis (DEA), ordinary least squares (OLS) and stochastic frontier analysis (SFA) (5).

This review sought to understand how efficiency and productivity analysis could be applied to Australian hospitals. To further this understanding, the review also investigated efficiency and productivity analysis of hospitals in Canada and the United Kingdom, on the basis of their similarities to Australia (each are developed economies, provide Universal Health Coverage and are roughly of similar population size).

This reviewed specifically addressed the following question:

What methodologies have been employed to measure the efficiency and productivity of hospitals in Australia, Canada and the United Kingdom? 


\section{Methods}

\section{Search strategy and selection criteria}

The literature search incorporated two different search strategies: (1) a search of grey literature sources using a Google search engine (Chrome) to access these sources; and (2) a traditional systematic review method search of academic databases.

As the hospital sector in Australia, Canada and the United Kingdom is largely Government funded, many studies of efficiency and productivity may fall into the category of 'grey literature.' Grey literature has been defined as 'that which is produced on all levels of government, academics, business and industry in print and electronic formats, but which is not controlled by commercial publishers' (7). These documents are typically published via web-based resources and coverage in academic journals is limited (8). To date, no 'gold standard' method for grey literature searches has been developed (8). The authors identified one methodological study(8) that provided comprehensive details for applying systematic review search methods to grey literature and that adheres to the PRISMA (Preferred Reporting Items for Systematic Reviews and Meta-Analyses) guidelines (9) and the methodology in this study was employed for this review.

\section{Selection criteria}

Selection criteria was defined by the researchers and are presented in Table 1.

Table 1

Selection criteria

\section{Inclusion criteria}

Published in English

Current version of the document

Included information on an efficiency and/or productivity study of a public or private hospital or a health service or hospital district or similar (i.e. a network of organizations that provides or makes arrangements to provide hospital care to a defined population)

\section{Exclusion criteria}

Not available in English

The document was a draft version that has been replaced with a more recent document

Did not include information on an efficiency and/or productivity study of a public or private hospital or a health service or hospital district or similar (i.e. a network of organizations that provides or makes arrangements to provide hospital care to a defined population)

Efficiency or productivity studies of sub-hospital organizational units, e.g. surgical wards

All years of publication were included

\section{(1) Grey literature}

The authors used Google Chrome to search and access relevant grey literature sources, including the websites of Australian, Canadian and United Kingdom Government Health Departments, Statistics, 
Accounting, Taxation and Productivity Offices and the websites of health economics research centres. The grey literature search was conducted between May 15th and July 20th 2018.

Due to the mechanism by which Google searches and returns results, it is impractical and unnecessary to screen all returned results. Google uses algorithms to rank the importance of website pages relevant to search terms, with relevancy of results decreasing with each page return.(10) The researchers therefore screened only the first 10 pages that were returned for each search.

The following keywords and phrases were included in the search: Efficiency, Productivity, Hospital, Health, Australia, Canada, United Kingdom, England, Northern Ireland, Wales

The keywords were combined in different formats using OR and AND. An example search strategy used was as follows:

(efficiency or productivity) AND Australia AND Hospital

\section{(2) Academic databases search}

The second search strategy of academic databases (Scopus, Web of Science, MEDLINE) was conducted during the month of August 2018. The lead author searched titles, abstracts and keywords in databases to obtain peer review journals that met the inclusion criteria. The same keywords used in the first search strategy were used in the database search by combining different words using "OR", "AND" and Truncation (*). A search strategy used in Scopus is presented in Table 2.

Table 2

Search strategy, Scopus

\begin{tabular}{|c|c|c|}
\hline & Search Strategy & Results \\
\hline 1. & TITLE-ABS-KEY ( "efficiency" ) & $2,157,342$ \\
\hline 2. & TITLE-ABS-KEY ( "productivity" ) & 344,898 \\
\hline 3. & TITLE-ABS-KEY ( "hospital" ) & $1,807,808$ \\
\hline 4. & TITLE-ABS-KEY ( austral*) & 569,878 \\
\hline 5. & $\begin{array}{c}\text { (TITLE-ABS-KEY ("efficiency") }) \text { OR ( TITLE-ABS-KEY ("productivity*" ) ) AND } \\
(\text { TITLE-ABS-KEY ("hospital" })) \text { AND ( TITLE-ABS-KEY }(\text { austral*)) }\end{array}$ & 871 \\
\hline
\end{tabular}

\section{Data extraction}

\section{(1) Academic databases}

The Title and Abstract of manuscripts were screened against the eligibility criteria. Manuscripts that did not address (either explicitly or implicitly) an analysis of the efficiency and productivity of hospitals or health service districts or similar in Australia, Canada or the United Kingdom were excluded. After title and abstract screening, the full texts were imported into Endnote and duplicates were removed. 


\section{(2) Grey literature}

Many grey literature documents do not have abstracts, therefore, executive summaries, table of contents or subheadings were screened. Document details, including the source organization, title, date published and URL, were recorded in a Microsoft Excel spreadsheet. The final documents were downloaded in full to ensure they addressed the research questions.

The combination of the three search strategies resulted in a total of 29 documents.

\section{Quality assessment}

This study does not seek to determine a quantitative outcome, but rather explore the methodologies that have been employed to assess the efficiency and productivity of hospitals in Australia, Canada and the UK. As such, no risk of bias assessment was made and a quality consideration of the documents included would not have had an impact on the thematic findings.

\section{Data analysis}

Studies were assessed to determine the type of efficiency and productivity analysis employed and the inputs and outputs selected for inclusion in the analysis.

The PRISMA Flow Diagram shown in Fig. 1 summarizes the search process used in this review.

\section{Results}

The review identified 31 documents that assessed the efficiency and productivity of hospitals in Australia, Canada and the United Kingdom. The below analyzes and compares these studies based on their country of origin, the type of efficiency and productivity analysis employed and the input, output and any other variables selected for inclusion in the analysis.

\section{National measures of hospital performance}

Within Australia, little work has been done to assess the efficiency and productivity of Australian hospitals. The Performance and Accountability Framework (the 'Framework') provides a national structure for reporting on public and private hospitals, and primary health organization performance (11). The Framework contains 48 indicators of health system performance, of which only four relate to efficiency. Data collection and reporting occurs for only two of these indicators and neither are a true measure of efficiency or productivity (12). Aside from the Framework, there are only a small number of studies (7) relating to the measurement of efficiency and productivity of Australian hospitals.

Similarly, within Canada, due to difficulties in data collection and recording, there is no national data available on the efficiency or productivity of Canadian hospitals. As noted by Ariste and Yu, the Canadian national accounting approach measures the total cost of inputs as total expenditures in publicly provided services, such as hospital care. This effectively means that total input costs are taken as total output, and 
it is therefore not possible to calculate the total factor productivity of the health sector $(13,14)$. Ariste and Yu therefore employ an episode-based direction measurement method that closely resembles the concept of output in the system of national accounts. This methods attempts to decompose expenditure changes across a given time period into a price change and a quantity change. Quantities measured are hospital inpatient and day surgery services with cost shares derived by using either the number of episodes for each major clinical category (MCC) or case mix group (CMG), or the number of episodes for each International Statistical Classification of Diseases and Related Health Problems, Tenth Revision, Canada clinical Chap. (13).

Despite the difficulties noted by Ariste and Yu, 12 studies have analysed the efficiency and productivity of Canadian hospitals. In addition, a number of studies have explored the measurement of health care sector output in Canada, including quantifying the cost function of various providers (14-17). Although these studies do not provide technical measures of efficiency and productivity and are therefore not further discussed in this review, they provide a useful exploration of the drivers of productivity in the health care sector and the difficulties in measuring the 'true' output of the health care sector, the improvement in length or quality of life in the population. A number of other studies also provide general discussion and overview of some of the challenges and key considerations in the measurement of productivity change in the Canadian health sector (18-20).

Unlike Australia and Canada, the United Kingdom has a well-developed national measure for assessing efficiency and productivity within the health system. The most significant body of work arises from the United Kingdom Office of National Statistics (ONS) and the Centre for Health Economics at University of York (21). The ONS provides measures of productivity for public service healthcare in the United Kingdom (and also England as a separate entity), (22) whereas the Centre for Health Economics considers only public service healthcare in the English National Health Service (NHS) (23). As both the ONS and the Centre for Health Economics investigate the productivity of public service healthcare, measures of input and output include primary care services (e.g. GPs) in addition to hospital care $(22,23)$. Each organisation provides a measure of productivity for the NHS as a whole by calculating the ratio of total quantity of healthcare output provided (adjusted for quality) with growth in the total quantity of inputs used $(22,23)$. However, as these productivity analyses relate to the whole NHS, as opposed to individual hospitals or Trust, they are considered outside the parameters of this review and are not further considered.

\section{Analysis Technique}

SFA is the analysis technique that has been used in the majority of efficiency and productivity studies of Australian hospitals (24-28). It is chosen for a number of reasons: it allows for measurement error, as opposed to attributing all the observed differences between hospitals to differences in technical efficiency; it can control for the influence of other unspecified environmental factors that may influence the relationship between outputs and inputs $(24,25,27,28)$; it provides a more conservative estimate of the scope to increase output (28); and it can identify the 'true' structure of the production function (24, 26). Whilst one study notes that the use of TFP indexing to measure the performance of government 
trading enterprises (which combines all outputs and inputs into a comprehensive measure of overall productivity) is increasing, TFP is not considered generally applicable to service provision, as it requires a price for each output and input and for many government enterprises it is not possible to identify output prices (29).

Studies in Australia that have adopted a DEA approach have done so as it provides a means to identify possible 'peers' or 'role models' by which benchmarks for performance can be established (29). This is particularly important for government agencies looking to control and standardise public expenditure on health services; it is interesting to note that of the two studies employing DEA in Australia, both were conducted by government agencies. Correspondingly, SFA is advantageous when it is the performance of the aggregate data set which is of interest, rather than any individual unit (24).

DEA, when used in Australia, was also selected for its inherent flexibility and its ability to handle multiple outputs where realistic price data for inputs and outputs is unavailable (24). However, as noted by Webster et al., a key drawback to the adoption of DEA is its assumption that there is no error in the data being studied (meaning that any identified inefficiencies are attributed to inefficiencies in the units under study, as opposed to random error) and the lack of a definite functional form encapsulating the production technology (24). This may be advantageous as there are fewer restrictions imposed on the model and less risks associated with mis-specified functional forms. But, input and output variables included in the model cannot be tested for significance, meaning that explanatory variables of little significance may be included in the model $(24,28)$.

In contrast to Australia, the majority of the Canadian studies identified utilise DEA, for a number of reasons: it accommodates multiple heterogeneous inputs and outputs to capture the complex nature of health service delivery (30-32), it does not rely on a priori assumptions in the specification of production frontiers (32) and the random error distribution (31); and it is less sensitive than SFA to underperforming outliers (31). No studies utilise SFA but three studies do utilise a Malmquist Productivity Index (MPI) in addition to DEA analysis (33-35). Like DEA, the MPI allows estimation of changes in overall productivity, but also allows decomposition into the efficiency change and technology change for each decision making unit over time (34). Asmild et al employ a slight variation of this approach, using the Malmquist Index of Asmild and Tam (36) that provides an overall measure of the movement of the frontier, as opposed to the standard approach that estimates the frontier shift specifically to each observation. This is advantageous as it can be applied to assess province specific frontiers for Ontario and New Brunswick, the provinces from which the sample of 114 public hospitals was drawn. These provinces differ substantially in their geography, Ontario being predominantly urban and New Brusnwick predominantly rural (33). This approach might therefore be also usefully applied within Australia, which has a similar geographic spread of hospitals.

Unlike Canada or Australia, DEA and SFA has had very limited use in assessing health system productivity and efficiency in England (37). This may in part be due to the number of governance models that have been place since the establishment of the NHS (38) that have shaped how efficiency and 
productivity is viewed. Following the introduction of an 'internal market' in 1991 in England, the official method adopted by the English Department of Health to promote efficiency gains was to undertake relative performance evaluation, whereby each the unit cost of were compared to those observed in other hospitals, with exogenous influences corrected for by using OLS methods. After correcting for these exogenous influences, residual unexplained cost differences were interpreted to represent inefficiency (39, 40). Reflecting this approach, a number of studies around this time utilise OLS (41). However, the use of this approach to make comparisons across organisations was later called into question, with some studies using SFA to raising concerns that residual unexplained costs differences should not be automatically attributed to inefficiency $(39,42)$. These are some of the few examples of SFA being used to assess productivity and efficiency in the United Kingdom.

As described above, the United Kingdom ONS provides measures of productivity for public service healthcare in the United Kingdom (and also England as a separate entity), (22) and the Centre for Health Economics at University of York have applied similar methods to individual hospitals and NHS Trusts (23). The Centre for Health Economics calculates the ratio of total quantity of healthcare output provided (adjusted for quality) with growth in the total quantity of inputs used and combines this with ordinary least squares regression to provide a measure of efficiency and productivity. This approach is touted as a mechanism to avoid some of the limitations of DEA whilst providing a means to investigate variations in hospital productivity (43). As outlined by Castelli et al the number of outputs produced by a hospital is usually far greater than the number of hospitals under consideration. DEA is only capable of dealing with multiple outputs up to a point determined by the number of organisations under consideration (43). To overcome this issue, Castelli et al draw on the prior work of Dawson (40) and Castelli et al (44) to propose an alternative approach to dealing with the problem of multiple outputs in DEA. This approach is an extension of the national accounting framework to measure changes in health productivity and involves the application of an explicit set of weights to combine diverse outputs into a single index, obviating the need for DEA (43).

Using this approach, Castelli et al construct productivity indexes for the financial years 2008/09 and 2009/10 for English NHS Hospital Trusts (43). The inputs and outputs used in the construction of these productivity indices is extensive and draws on a number of input and output factors to construct composite input and output indices. This approach has been highly influential in considering the productivity and technical efficiency of hospitals across the UK and has been adopted and modified by a number of subsequent studies. A similar approach is employed in a subsequent study by Bojke et al that measures NHS productivity growth as a set of paired year-on-year comparisons from 1998/1999$1999 / 2000$ through to $2012 / 2013-2013 / 2014$ (45). Aragon et al broaden the definition of outputs to more fully reflect the array of diverse activity provided by hospitals (46).

Outside of England, a small number of studies adopt DEA, often in combination with Malmquist Indices. Malmquist approaches are often employed in Scotland, as the Scottish NHS is more socially driven as compared to the current governance model of the English NHS. Because of this framework, typical economic specifications such as cost minimisation or profit maximization are not appropriate (47) 
(Scottish hospitals are funded via block contract). The Malmquist index, which does not require input or output prices, is therefore a common approach in this health sector.

Table 3 identifies the analysis technique by country for each study identified in this review. 
Table 3

Analysis techniques utilised in efficiency and productivity studies of Australian, Canadian and United Kingdom hospitals

\begin{tabular}{|c|c|c|}
\hline Analysis Technique & Country & Authors (year), publication \\
\hline $\begin{array}{l}\text { Average cost per } \\
\text { case }\end{array}$ & Australia & Braithwaite et al (2006), Health Services Management Research \\
\hline DEA & Australia & $\begin{array}{l}\text { Steering Committee for the Review of Commonwealth/State } \\
\text { Service Provision (1997), Australian Government }\end{array}$ \\
\hline DEA & Canada & Chowdhury and Zelenyuk (2016), Omega \\
\hline DEA & Canada & Allin et al (2016), Health, Economics Policy and Law \\
\hline DEA & Canada & Allin et al (2015), Healthcare Policy \\
\hline DEA & Canada & Abeney and Yu (2015), Lakehead University \\
\hline DEA & Canada & Fixler et al (2014), Health Services Management Research \\
\hline DEA & Canada & $\begin{array}{l}\text { Canadian Institute for Health Information (2014), Canadian } \\
\text { Government }\end{array}$ \\
\hline DEA & Canada & Gruca and Nath (2001), Healthcare Management Science \\
\hline DEA & Canada & Biodeau et al (2009), Applied Economics \\
\hline DEA & Canada & Bilodeau et al (2004), Journal of Productivity Analysis \\
\hline DEA & Scotland & Ferrari (2006), The Service Industries Journal \\
\hline DEA & $\begin{array}{l}\text { Northern } \\
\text { Ireland }\end{array}$ & McCallion et al (2000), Applied Economics \\
\hline DEA & Scotland & $\begin{array}{l}\text { Hollingsworth and Parkin (1995), Mathematical Medical and } \\
\text { Biology: A Journal of the IMA }\end{array}$ \\
\hline $\begin{array}{l}\text { DEA } \\
\text { Malmquist Index of } \\
\text { Asmild and Tam }\end{array}$ & Canada & Asmild et al (2013), journal of Productivity Analysis \\
\hline $\begin{array}{l}\text { DEA } \\
\text { Malmquist } \\
\text { Productivity Index }\end{array}$ & Canada & $\begin{array}{l}\text { Chowdhury et al (2014), International Journal of Production } \\
\text { Economics }\end{array}$ \\
\hline $\begin{array}{l}\text { DEA } \\
\text { Malmquist } \\
\text { Productivity Index }\end{array}$ & Ireland & Gannon (2008), Applied Economics Letters \\
\hline $\begin{array}{l}\text { DEA } \\
\text { SFA } \\
\text { OLS }\end{array}$ & Australia & Webster et al (1998), Australian Government \\
\hline $\begin{array}{l}\text { Malmquist } \\
\text { Productivity Index }\end{array}$ & Canada & $\begin{array}{l}\text { Chowdhury et al (2011), International Journal of Productivity and } \\
\text { Performance }\end{array}$ \\
\hline Malmquist & Scotland & Valdmanis et al (2017), Health Services and Outcomes Research \\
\hline
\end{tabular}




\begin{tabular}{|lll|}
\hline $\begin{array}{l}\text { Productivity Index } \\
\text { Productivity Index }\end{array}$ & Scotland & Maniadakis et al (1999), Healthcare Management Science \\
\hline OLS & Scotland & Scott and Parkin (1995), Health Economics \\
\hline Productivity ratio & England & Aragon et al (2017), PLOS ONE \\
\hline Productivity ratio & England & Castelli (2015), European Journal of Health Economics \\
\hline SFA & Australia & $\begin{array}{l}\text { Yong, Karen and Harris, Anthony (1999), Centre for Health } \\
\text { Program Evaluation }\end{array}$ \\
\hline SFA & Australia & Wang, Zhao and Mahmood (2006), IZA Discussion Paper Series \\
\hline SFA & Australia & $\begin{array}{l}\text { Gabbitas and Jeffs (2008), 30th Australian Health Economics } \\
\text { Conference }\end{array}$ \\
\hline SFA & Australia & Productivity Commission (2009), Australian Government \\
\hline SFA & Scotland & Ferrari (2006), Applied Economics \\
\hline SFA & England & Street and Jacobs (2002), Applied Economics \\
\hline SFA & England & Street (2003), Health Economics \\
\hline
\end{tabular}

\section{Outputs}

A hospital's performance should ideally be measured in terms of patient outcomes, the improvement in physical and emotional wellbeing relative to what would otherwise be the case if they had not sought treatment from a hospital (48). Within Australia, there is limited data available to directly measure the changes to patient health outcomes (28). As such, studies within Australia have largely employed proxy measures to indirectly account for changes in health outcomes. These proxy measures are usually measurable hospital outputs, such as number of separations, $(25-27,29,49)$ number of occupied bed days $(24)$ or occasions of service $(24,26)$. A number of Canadian studies also employ similar proxy outcomes, relating to discharges, inpatient days, outpatient and surgical visits $(30,32-35,50-52)$.

Occasionally, 'quality of care' is also used as a proxy measure for health outcomes, with one study in Australia including risk-adjusted mortality ratios for each hospital in the analysis to provide some measure of hospital quality (28). Similarly, Abeney and Yu in their assessment of the efficiency of Canadian health provinces select the median wait time between various treatment phases and the median wait time for access to medical imaging resources as their output measure (53).

There are studies in Canada and the United Kingdom, however, which have developed methods that better approximate the changes to patient health outcomes. Three studies in Canada use provincial health regions as their decision making unit, rather than individual hospitals, and this has allowed these studies to incorporate a measure of patient outcomes into the efficiency and productivity analysis $(31,54,55)$. For each study, the selection of outputs was determined in consultation with a range of stakeholders in 
these health regions, including senior health ministry officials. The consensus was that any measure of efficiency should be measured against the objective of providing access to effective care to those who are sick or otherwise in need of care. To measure this objective, each study selected an output variable of the reduction of Potential Years of Life Lost (PYLL) for causes of death that are considered amenable to health system intervention, such as sepsis, pneumonia, colorectal cancer, breast cancer in women, hypertensive diseases, asthma and most other respiratory diseases, renal failure, pregnancy and childbirth. In each case, rates of PYLL per 100,000 population for the latest available time period were age-standardised to account for the different age structures across regions. Estimates were based on Canada's vital statistics database held at Statistics Canada $(31,54,55)$.

Utilising the health region as the decision making unit in the analysis facilitated the use of these health outcome measures, as apart from a few exceptions, population health data was available at the regional level. Reduction in PYLL can still be considered a proxy for individual health outcomes, as it is effectively a measure of premature mortality and does not address quality of life; reduction in PYLL may also be influenced by factors outside the health system, including social determinants of health (e.g. socioeconomic status) and other factors, such as smoking rates. To address this, a number of these 'environmental factors' were included as inputs in the DEA analysis and in a subsequent regression analysis to identify the factors that help explain variation in inefficiency across regions. Factors not significantly associated with the outcome measure were included as factors only in the subsequent regression analysis.

Castelli et al include a similar measure for patient outcome in their construction of productivity indexes for English NHS Hospital Trusts (43). The output index includes a measure of quality, by constructing the equivalent of a Quality-Adjusted Life year (QALY) profile for patients allocated to each Healthcare Resource Group (HRG). Although this equivalent QALY profile is still somewhat a proxy measure of patient health outcomes, as it relies heavily on average measures and standardisation across age and gender, it is a significant step forward in accounting for health outcomes as a measure of hospital output and an approach which has not yet been adopted in Australia. Given that across Australia most states have adopted a similar organisational structure to United Kingdom and Canadian health regions, with individual hospitals and related health service providers in a given geographic region under the auspices of a Hospital and Health Service or Local Health Network, it may be worthwhile to consider similar analytic approaches in the Australian context.

Further confounding the selection of an appropriate output measure is the casemix - the mix of types of patients - treated by the hospital. Hospitals with a casemix of relatively ill or complicated patients (such as those with multiple morbidities) will likely require a higher level of input to produce the same number of outputs if outputs are measured in aggregated terms such as number of bed days or number of patients treated (i.e. such patients will have higher treatment costs). Within Australia, the introduction of casemix funding and diagnosis-related groups (DRGs) (a means of grouping patients based on the type of treatment received) (56) has provided a mechanism to account for variations in hospital casemix when conducting efficiency and productivity analyses. 
Of the efficiency and productivity analyses of Australian hospitals only two eschew a casemix adjusted output. Gabbitas et al estimate a series of three input stochastic frontier models for public acute care hospitals in each State and Territory for the period 1996-1997 to 2005-2006 (27). They use a single output, the number of casemix adjusted separations from each State and Territory's public acute care hospital system. While the separations are casemix adjusted at some point during data collection, the output used in the study is the total number of separations, with no attempt to weight this output variable with some measure of disease complexity, such as DRGs.

An Australian Bureau of Statistics study measuring the efficiency and productivity of Australian private hospitals also does not employ a casemix approach, but does make some attempt to account for the confounding nature of patient complexity (24). The study uses output measures based on the number of acute care and surgery inpatient occupied bed days, occasions of service and acute care separations. This approach was adopted after difficulties in applying disease-costing weights to separation data (the level of aggregation in grouping diseases was too high to effectively reweight the raw separations) and attempts to provide some adjustment for disease severity. The study goes on to acknowledge the potential of DRGs to effectively account for hospital casemix.

Issues with aggregation of disease groupings remains a challenge even when DRGs are utilised. A DEA study of the efficiency of 109 hospitals in Victoria using data for the period 1994-95 utilised two output measures: unplanned re-admissions rate (an imperfect proxy for the quality of care); and the number of patients treated by each hospital expressed in terms of weighted inlier equivalent separations (WIES), aggregated into three categories based on the degrees of complexity of each WIES. The WEIS are said to be aggregated into only three categories due to difficulties in incorporating the over 500 DRG variables into the DEA analysis (29).

Similarly, the Productivity Commission analysis of 508 public and private acute hospitals in Australia aggregated output variables into five major diagnostic categories (MDCs): acute separations; pregnancy and neonate separations; mental and alcohol separations; other seperations; and endocrine, nutritional and metabolic diseases and disorders.(48) Similar to the above study, this aggregation occurs due to concerns that using the full 23 MDCs would represent too many variables in the SFA analysis, particularly when more complex functional forms are employed (48).

Wang et al also acknowledges that as the number of diseases and conditions for which patients seek treatment is large (DRG categories), some degree of aggregation of hospital outputs is necessary to avoid running out of degrees of freedom in the efficiency analysis.(26) In their investigation of the efficiency of New South Wales hospitals using SFA, the authours use an 'inpatient service index, incorporating the number separations and an index for the DRG diagnostic category to account for casemix variation (26). Yong et al employ a similar approach utilising WIES in their estimate of the efficiency of public hospital in Victoria by SFA (25).

Unlike Australia, Canadian hospitals are funded under a global budget model, rather than a casemix approach. Under global budgets, a fixed amount of funding, typically based on factors like historical 
funding amounts or population, is provided to a hospital or other health care provider and that provider then delivers services to patients for a fixed period of time (usually one year) (57).

Despite this, a number of methodologies have been developed to adjust patient flows for casemix, including Case Mix Groups (CMD) methodology $(32,34)$ or Resource Intensity Weights (RIW) $(30,33,50)$ or Expected Length of Stay (ELOS) (30). The Case Mix Groups methodology identifies clusters of acutecare inpatients with similar clinical and resource-utilization characteristics and adjusts for various factors -such as patient age, sex and comorbidities (the number of conditions a patient has beyond the primary reason he or she was admitted into a hospital) - to account for how they may influence the costs of hospital stays (32). RIW is a relative value measuring the total patient resource use compared with average typical acute inpatients. ELOS is the average acute length of stay in hospital for patients within the same CMP, age category, comorbidity level and intervention factors (58).

Hospital payment arrangements differ significantly across the United Kingdom, with two distinct models of governance in place. In England, funding commissioners contract with providers to deliver care, with patients empowered to exercise choice between providers (38). Reimbursements for care provided is made at nationally determined DRG rates (known as Health Resource Groups (HRGS) in the UK) (59). Within England, HRGs are used to adjust for casemix in efficiency and productivity studies. Castelli et al in their construction of productivity indexes for English NHS Hospital Trust draw on a number of input and output factors to construct composite input and output indices, including an adjustment for casemix through the use of HRGs (43) and this approach has been used in a number of subsequent studies (45, 46).

Within Scotland and Wales regional health boards are responsible for providing primary and secondary care to their communities and are funded to deliver this care. This is also largely the case in Northern Ireland. As with Canada, DRGs are not utilised in these countries, with payments to hospitals and other health service providers in the form of block contracts. Given these differences in funding models, casemix adjustment approaches are rarely employed in studies outside England.

\section{Inputs}

Inputs in efficiency and productivity analysis are generally broken down into labour, materials and capital. The degree of further disaggregation across these categories is variable. Some studies distinguish between the various types of labour - nursing staff, allied health staff, administrative staff, etc. $(24,25$, 28 ) - while others simply use an aggregate measure of total employment (27) or a crude split into medical and non-medical staff $(26,29)$. Of note, the few studies that assess the efficiency of Canadian provinces, rather than individual hospitals $(31,55,60)$ also employ input variables relating to the type of services and the heath service providers in the region, such as Hospitals, Other Institutions and Public Health Services.

Within Australia, the treatment of capital can vary dependent on the funding arrangements of the hospitals under analysis. Yong et al consider that capital-related data such as depreciation and interest 
are poor estimates of the price of capital, as the Victorian hospitals analysed in their study do not own their buildings and assets and are not generally depreciated in public hospital accounting systems, nor do they pay interest (25). Gabbitas et al, however, include real capital services in their analysis of public acute care hospital in each Australian State and Territory (27).

The 1997 Steering Committee for the Review of Commonwealth/State Service Provision use an aggregate measure of non-labour costs in their efficiency analysis of Victorian public hospitals that excludes capital stock, due to limitations in data availability (29). Similarly, other studies report difficulties in adequately measuring capital (24) and instead use proxy measures, such as number of beds, where more extensive capital measures are unavailable (28).

The treatment of material costs within Australia also varies. Some studies exclude completely (25), assuming that the purchasing power of hospitals means that the price of materials is the same across hospitals and can thus be reasonably excluded from the analysis (26); others use a nominal or total expenditure on medical and drug supplies $(27,28)$. Thus, the availability of accurate data for material and capital assets is often a significant challenge when examining the efficiency and productivity of hospitals.

Table 4 identifies input and output variables used for each study, grouped by country. 
Table 4

Inputs and output variables utilized in efficiency and productivity studies of Australian, Canadian and United Kingdom hospitals

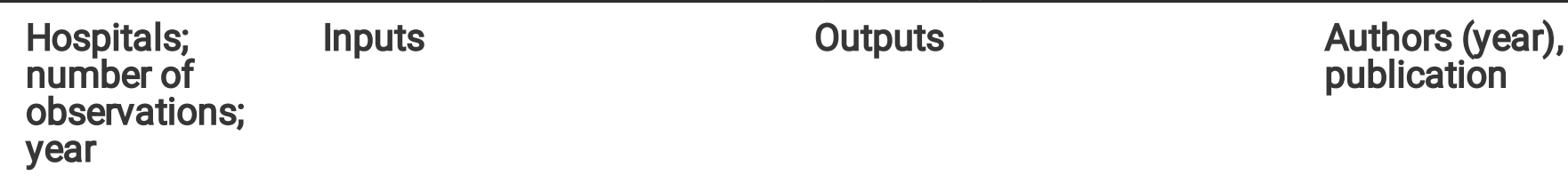

\section{Australia}

$\begin{array}{lll}\text { Victorian } & \text { FTE non-medical staff } & \text { WIES with intensity rate < } \\ \text { public } & \text { FTE medical staff } & 0.2(\mathrm{Y} 1) \\ \text { hospitals; 109; } & \text { Non-salary costs } & \text { WIES with intensity rate }> \\ \text { 1994-1995 } & & 0.2 \text { and, } 0.4(\mathrm{Y} 2) \\ & & \text { WIES with intensity rate }> \\ & 0.4(\mathrm{Y} 3) \\ & & \text { Inverse of the unplanned re- } \\ & \text { admission rate }\end{array}$

Private SMO (FTE)

hospitals; 301

(cross-

section), 280

(panel); $1994-$

1995 (cross-

section), 1991-

992 - 1994-

Beds

costs)

Admissions
1995 (panel)
VMO (\$ contract value)

Nursing staff (FTE)

Other staff (FTE)

Materials (non-labor

Total staff (FTE)

Total staff (labor costs, \$)

Parametric (SFA and

OLS):

Beds

Capital stock

Materials (non-labor

costs)

Materials (including

VMOs)

Total staff (total FTE)

Total staff (labor costs)
Acute care inpatient days

(psychiatric care inpatient

days, rehabilitation days,

medical care days)

Surgery inpatient days

(advance surgery days,

surgery days, minor surgery

days, obstetrics days)

Non-inpatient occasions of

service

Nursing home type

inpatient days

Surgical procedures

Acute care inpatient

separations

Accident/emergency

Composite output (of the

above)

Total inpatient revenue

Parametric (SFA and OLS):

Revenue

Composite output

(occupied bed days)

Victorian

public

hospitals; 35;

1994-1995

New South

Wales public

hospitals; 114;

1997-1998
Average medical, nursing, administration/clerical, hotel and allied, medical support and RMO salary per E.F.T

Average salary of medical officer and visiting medical officers Average salary of nonmedical labor input
Weighted Inlier Equivalent

Separations

Total Operating Expenditure

Inpatient Service Index (the proportion of a hospital's separations times a weight corresponding to the average length of stay of separations with AN-DRG) OOS

Average Available beds

Same day separations \% total separations
Steering Committee

for the Review of

Commonwealth/State

Service Provision

(1997), Australian

Government

Webster et al (1998),

Australian

Government
Yong, Karen and Harris, Anthony (1999), Centre for Health Program Evaluation

Wang, Zhao and Mahmood (2006), IZA Discussion Paper Series 
Average length of stay of acute episodes

Cost per Outpatient OOS

Cost per emergency OOS

Presentations to emergency department

Teaching

hospitals in

New South

Wales and

Victoria; 20;

1991-1992 to

1996-1997

(NSW) and

1991-1992 -

19995-1996

(Vic)

State and

Territory

(n) lic acute

hospitals;

1996-1997 to

2005-2006
Cost per DRG-weighted

patient (NSW)

WEIS (Victoria)
Braithwaite et al (2006), Health

Services

Management

Research
State and

Territory

public and

private acute hospitals; 508; 2006-2007
FTE employment in public

acute care hospitals

Real capital services

Real medical supplies
Number of casemixadjusted separations
Gabbitas and Jeffs (2008), 30th Australian Health Economics Conference

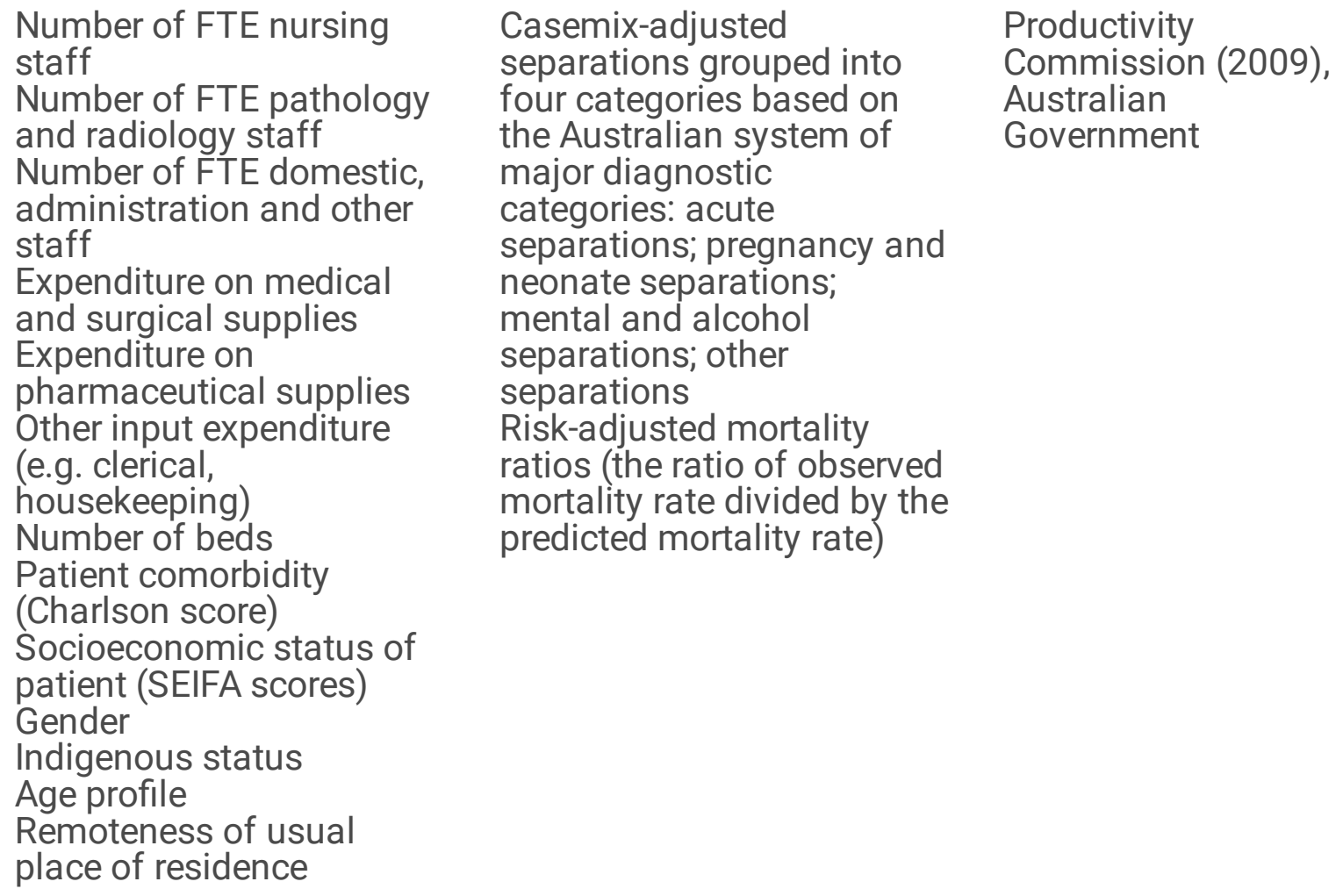

Productivity Commission (2009), Australian Government

Number of FTE nursing staff Number of FTE pathology and radiology staff Number of FTE domestic, administration and other staff Expenditure on medical and surgical supplies Expenditure on pharmaceutical supplies Other input expenditure (e.g. clerical, housekeeping)

Number of beds

Patient comorbidity

(Charlson score)

Socioeconomic status of patient (SEIFA scores)

Gender

Indigenous status

Age profile

Remoteness of usual

place of residence

Casemix-adjusted separations grouped into four categories based on the Australian system of major diagnostic categories: acute separations; pregnancy and neonate separations; mental and alcohol separations; other separations Risk-adjusted mortality ratios (the ratio of observed mortality rate divided by the predicted mortality rate)

\section{Canada}

113 acute-care hospitals in Ontario; 2003 and 2006
Administrative staff hours

Nursing hours

Staffed beds

Medical-surgical supplies
Ambulatory visits

Chowdhury and

Zelenyuk (2016), Omega 
costs

Non-medical supplies

costs Equipment expenses

$\begin{array}{llll}\begin{array}{l}89 \text { health } \\ \text { regions; 2007- }\end{array} & \text { Inputs - spending per } & \text { Output - age standardised, } & \text { Allin et al (2016), } \\ 2009 & \text { capita (\$) Hospitals } & \text { per 100,000 population } & \text { Health, Economics } \\ & \text { Prescription drugs } & \text { PYLL from treatable causes } & \text { Policy and Law } \\ & \text { Physicians } & \text { (before age 80) PYLL from } & \\ & \text { Residential care facilities } & \text { treatable causes (before } & \\ & \text { Community nurses } & \text { age 75) PYLL from } \\ & \text { Inputs - environmental } & \text { treatable causes (before } \\ \text { adjustors } & \text { age 85) Mortality from } \\ \text { Education (per cent with } & \text { treatable causes (before } \\ \text { high school or more) } & \text { age 80) } \\ \text { Recent immigrants (per } & \text { Survival rate from treatable } \\ \text { cent) Non-Aboriginal (per } & \text { causes (before age 80) } \\ \text { cent) } & \end{array}$

89 health

regions
Spending per capita \$

Hospitals

Prescription drugs

Physicians

Residential care facilities

Community nurses

Inputs - environment

Education (\% with high

school or more)

Recent immigrants (\%)

Non-Aboriginal (\%)

\section{Canadian}

provinces;

2001-2010
Capital: Residential care

facility beds

Labour: Pharmacists,

Nurse practitioners,

Specialists, Medial

laboratory technologists

General practitioners

Machine:, CT scanners

MRI

For the expenditure input

variables, the following

proxies are used:

Capital: Hospitals, Other

institutions Other capitals

Labour: Physicians, Other

professionals,

Administration

Machine: Other health

spending

Services: Public health, Drugs
154 acute care

hospitals; 1

April 2005 - 31

March 2006
Service Recipient

Workload Units: e time spent by Unit Producing

Personnel performing service recipient activities of the hospital.

Bed Days staffed and in operation: (bed days)
PYLL from treatable causes

(before age 80), per

Allin et al (2015),

100,000 population, age

standardized
Healthcare Policy
Median waiting time between General Practice visit, Specialist visit and Treatment Median Weeks Waiting Time for Computed tomography scanner, Magnetic Resonance Imaging and Ultrasound
Abeney and $\mathrm{Yu}$ (2015), Lakehead University
Inpatient/Resident

Discharges and Deaths.

Outpatient visits

Inpatient surgical visits

Outpatient surgical visits

Resource Intensity Weight:

resource allocation metric

for estimating the costs of
Fixler et al (2014), Health Services Management Research 
measures the calendar days that beds and cribs are available and staffed to provide services to inpatients and residents. It is a measure of the hospital's capital input.

acute inpatient and day surgical cases, using clinically homogenous groups

Expected Length of Stay: represents an estimation of the typical length of stay for acute inpatient cases.

113 acute care hospitals in Ontario; 20022006
Human resources including nurses and administrative workers measured in FTE hours Purchased services and supplies including medical/surgical supplies and nonmedical/surgical supplies measured in dollars

Number of staffed beds as a proxy for capital.

Canadian health regions
Spending per capita \$

Hospitals

Prescription Drugs

Physicians

Residential Care Facilities

Community Nurses

Inputs - Environmental

Factors

Education (High School or

More) (\%) Recent

Immigrants (\%)

Non-Aboriginal Persons

(\%)
Model 1 used unadjusted inpatient days and outpatient visits, Model 2 used case-mix adjusted weighted inpatient days and outpatient visits as outputs Model 3 included unadjusted inpatient days, outpatient visits and the case-mix index as outputs.
PYLL From Treatable Causes (Before Age 80), per 100,000 Population, AgeStandardized
Chowdhury et al (2014), International Journal of Production Economics
Canadian Institute for Health Information (2014), Canadian Government

\author{
Resource Intensity Weight- \\ adjusted discharges \\ Asmild et al (2013), \\ journal of Productivity \\ Analysis
}

five categories of nursing

for each acute care

hospital in each of the

provinces

114 public

Ontario and

New

Brunswick;

1998-2004
113 acute care hospitals in Ontario; $2002 / 2003$ to $2005 / 2006$
Human resources including FTE hours for nurses and administrative workers Purchased services and supplies including medical/surgical and non medical/surgical supplies Number of staffed beds as a measure of capital Total equipment expense as a proxy of service-mix
Inpatient and outpatient volume
Chowdhury et al (2011), International Journal of Productivity and Performance
Nursing (FTE)

Ancillary services (FTE)

Administration (FTE)

Services and supplies
Inpatient cases weighted by

Resource Intensity Weights

Weighted outpatient visits

Long-term days of care 
hospitals in including drugs and

Ontario; 1986 medical-surgical supplies

(\$00000's CN)

Total beds

121 short-term

hospitals in

Quebec;

$1981 / 82-$

$1992 / 93$
Total number of hours and

expenses on labor

Supplies expenditure

(medical, administrative,

maintenance, security and

capital maintenance)

Food and meals prepared

for inpatients

Drugs

Energy
Inpatient days

Outpatient clinic visits

Laboratory exams

performed for pay (for non-

hospitalized patients)

Laundry and cafeteria

services (for non-

hospitalized patients)

Teaching
Biodeau et al (2009),

Applied Economics
Total number of hours and expenses on labor

Supplies expenditure

(medical, administrative, maintenance, security and capital maintenance)

Food and meals prepared

for inpatients

Drugs

Energy
Average number of patient days

Average number of clinic visits

Average number of patient

days

Average number of clinic

visits
Bilodeau et al (2004), Journal of

Productivity Analysis

\section{United Kingdom}

\begin{tabular}{|c|c|c|c|}
\hline $\begin{array}{l}43 \text { general } \\
\text { acute care } \\
\text { Scottish } \\
\text { hospitals; } \\
2003-2007\end{array}$ & $\begin{array}{l}\text { Doctors (physicians and } \\
\text { dentists) FTE } \\
\text { Nurses (nurses in all } \\
\text { categories including nurse } \\
\text { trainees) FTE } \\
\text { Other labor (all other labor } \\
\text { inputs) FTE } \\
\text { Staffed beds (a proxy for } \\
\text { capital) }\end{array}$ & $\begin{array}{l}\text { Inpatient cases (inpatient } \\
\text { elective cases and inpatient } \\
\text { emergency cases) adjusted } \\
\text { for Healthcare Resource } \\
\text { Group categories } \\
\text { Outpatient and short stay } \\
\text { patients (inpatient day } \\
\text { cases, clinic attendances } \\
\text { and emergency ward } \\
\text { attendances) }\end{array}$ & $\begin{array}{l}\text { Valdmanis et al } \\
\text { (2017), Health } \\
\text { Services and } \\
\text { Outcomes Research } \\
\text { Methodology }\end{array}$ \\
\hline
\end{tabular}

English NHS

Trusts;

2010/11 -

2012/13
NHS Labour (Direct)

Agency Labour

Intermediate goods and services Capital
Elective and day cases

Non-Electives A\&E

Chemo/Radiotherapy \&

High Cost Drugs

Community Care

Community Mental Health

Diagnostic Tests

Hospital/Patient Transport

Scheme Other NHS Activity

Outpatient Radiology

Rehabilitation Renal

Dialysis

Specialist Services

Elective and day cases:

Number of patients

Mean 30-day post

discharge survival rate

Mean life expectancy in years
Aragon et al (2017), PLOS ONE
English NHS

Hospitals;

2009/10
NHS labour

Agency labour

Intermediate goods and

services

Capital
Castelli (2015),

European Journal of Health Economics 
80th percentile waiting

times

Non-electives:

Number of patients

Mean 30-day post survival

rate

Mean life expectancy in

years

Outpatient volume of

activity

Acute

hospitals in

Ireland; 1995-

1998
Average number of beds

per year

Inpatients (total number of discharges and deaths)

Outpatients (total yearly

number of attendances)

Both adjusted for casemix

using DRGs
Gannon (2008),

Applied Economics

Letters

Number of people employed in each hospital (FTE)

\begin{tabular}{|c|c|}
\hline $\begin{array}{l}3 \text { acute } \\
\text { cottish } \\
\text { sspitals; } \\
91 / 92- \\
96 / 97\end{array}$ & $\begin{array}{l}\text { Total capital charges } \\
(£ 000) \\
\text { Medical staff FTE } \\
\text { Nursing staff FTE } \\
\text { Other staff FTE } \\
\text { Total number of beds. }\end{array}$ \\
\hline $\begin{array}{l}\text { acute } \\
\text { ottish } \\
\text { spitals; } \\
91 / 92 \text { to } \\
96 / 97\end{array}$ & $\begin{array}{l}\text { Total capital charges } \\
\text { Medical staff FTE } \\
\text { Nursing staff FTE } \\
\text { Other staff FTE } \\
\text { Total number of beds }\end{array}$ \\
\hline
\end{tabular}

217 English

NHS hospitals;

1995-1996

Average Expected costs

Average Actual costs

Ferrari (2006), The

Inpatients ( surgery,

medical other)

Day cases and day

Service Industries

patients. Journal

Total number of cases weighted by casemix

Ferrari (2006), Applied Economics

226 English

NHS hospitals;

1995-1996

23 Northern

Island

Hospitals;

1986-1992
Average Expected costs

Average Actual costs

Total number of inpatients and outpatients

Nursing staff

Administrative staff
Street and Jacobs (2002), Applied Economics

Street (2003), Health Economics

McCallion et al (2000), Applied Economics
Ancillary staff (measured

by full time equivalent

staff members)

Specialists

Bed complement

75 Scottish hospitals; 1991/92 $1995 / 1996$
Admissions for stroke Admission for fractured neck of femur Admission for myocardial infraction
Standardised survivals after admission for stroke Standardised survivals after admission for fractured neck of femur Standardised survivals after admission for myocardial infraction
Maniadakis et al (1999), Healthcare Management Science 


\begin{tabular}{|c|c|c|c|}
\hline $\begin{array}{l}75 \text { acute } \\
\text { Scottish } \\
\text { hospitals; } \\
\text { financial year } \\
1992-93\end{array}$ & $\begin{array}{l}\text { Average number of staff } \\
\text { beds } \\
\text { Total number } \\
\text { professional, technical, } \\
\text { administrative and clerical } \\
\text { staff } \\
\text { Total of junior and senior } \\
\text { non-nursing medical and } \\
\text { dental staff (staff number } \\
\text { measured as the average } \\
\text { effective staff number for } \\
\text { the year } \\
\text { Cost of drug supply } \\
\text { Capital charge }\end{array}$ & $\begin{array}{l}\text { Acute in-patient days } \\
\text { (medical) } \\
\text { Acute in-patient days } \\
\text { (surgical) } \\
\text { Accident and emergency } \\
\text { attendances } \\
\text { Out-patient attendances } \\
\text { Obstetrics and gynaecology } \\
\text { in-patient days } \\
\text { Other speciality in-patient } \\
\text { days }\end{array}$ & $\begin{array}{l}\text { Hollingsworth and } \\
\text { Parkin (1995), } \\
\text { Mathematical } \\
\text { Medical and Biology: } \\
\text { A Journal of the IMA }\end{array}$ \\
\hline $\begin{array}{l}76 \text { acute } \\
\text { Scottish } \\
\text { Hospitals; } \\
\text { 1992/93 }\end{array}$ & Number of staffed beds & $\begin{array}{l}\text { Number of discharges and } \\
\text { average length of stay for } \\
\text { acute surgical/medical and } \\
\text { other specialties } \\
\text { Number of outpatient, } \\
\text { accident and emergency } \\
\text { and day case attendances }\end{array}$ & $\begin{array}{l}\text { Scott and Parkin } \\
\text { (1995), Health } \\
\text { Economics }\end{array}$ \\
\hline
\end{tabular}

\section{Other variables}

In addition to the above identified input and output variables, a number of studies have identified an outstanding need to account for the differences between hospitals in terms of the services they provide, the patients they treat and their operational structures. Yong et al note that teaching hospitals typically perform more complex, innovative or rare procedures that may not be adequately reflected or captured by the inclusion of volume or casemix adjusted variables. They therefore include two dummy variables in their analysis to account for variation in costs across different types of hospitals in Victoria (25). Similarly, given expected differences in operating structures between metropolitan/large country and small rural hospitals in Victoria, the Steering Committee for the Review of Commonwealth/State Service Provision divides their sample of Victorian hospitals into the above two categories when making their assessment of efficiency (28).

A number of Canadian studies also distinguish between hospitals based on their size $(32,50,52)$, geographic location $(32,50)$, teaching status $(32,52)$, and ownership type (government, religious, secular, not-for-profit) (50). Like Yong et al, Chowdhury et al make these distinctions between hospitals by inclusion of dummy variables in the DEA analysis (32), whilst Gruca et al utilise a nested DEA model to compare across hospital types (50) and Bilodeau et al utilise correlation coefficients (52). Given the similarities in geography and demography between Canada and Australia, it is unsurprising that variables relating to geographic location, size and teaching status were selected.

In their assessment of efficiency and productivity of English NHS Hospital Trusts, Castelli et al investigate variations in hospital productivity using ordinary least squares regressions (43). They utilise a number of explanatory variables identified in the literature as exerting an influence over performance at the hospital level, including variables such as the proportion of patients receiving some form of specialised care, teaching hospitals and Foundation Trust versus non-Foundation Trusts and the proportion of emergency 
admissions over total admissions (43). Similar approaches using regression analysis to investigate potential explanatory variables are also evident in a number of Canadian studies $(31,54,55)$.

The Productivity Commission in their 2009 paper utilise a number of additional variables to account for differences in the nature and activities of hospitals across Australia, including the proportion of patients who are not treated as public patient as a proxy measure for the different levels of resources used by hospitals to treat public and non-public patient; and Evans and Walker information indices. These are measures of the relative complexity of work undertaken by a hospital, where the amount of information a hospital learns from an admission is inversely related to the likelihood of that case occurring within the system and that likelihood of that hospital treating that particular case $(28,61)$. Abeney and Yu utilise a regression analysis subsequent to their efficiency and productivity analysis to correct efficiency scores for the environmental and behavioural factors of patients, such as high blood pressure, asthma, postsecondary education, access to regular doctors, that may be present in a region's patient population (53).

The inclusion of these types of additional variables is of particular importance, as it acknowledges that there are additional, indirect factors, such as the location and teaching status of the hospital that may influence a hospital's efficiency and productivity. As teaching and research activity in Australia's public hospitals increases (driven by initiatives such as the Medical Research Future Fund (62)), it will become increasingly important to capture the impact of this activity on overall hospital efficiency.

\section{Discussion}

Approaches to productivity and efficiency analysis vary across Australia, Canada and the United Kingdom, but a number of common themes arise that can inform future studies of productivity and efficiency within Australia. These relate to national efforts to develop frameworks to assess health system efficiency; the selection of inputs, outputs and analysis technique; and the lack of integration and uptake of efficiency and productivity analysis into the health system.

Australia, the United Kingdom and to some degree Canada each have a national mechanism to assess the efficiency of public hospitals $(12,13,21)$. However, these national systems do not provide true estimates of efficiency and therefore cannot be used to robustly identify areas of inefficiency across decision making units. As a result, a number of papers have called for improved frameworks and mechanisms to assess public hospital efficiency and productivity $(20,28)$ and there remains an outstanding need, particularly within Australia, for a comprehensive efficiency and productivity model that can be applied across the public hospital sector. Critical to any such model will be access to and availability of data, and the selection of appropriate inputs and outputs.

The selection of appropriate input and output variables is essential for robust measurement of public hospital efficiency and productivity. Input variables utilised by the studies identified in this review were similar, consisting of measures of labour (most commonly relating to full time equivalent employees), goods and services, e.g. purchased consumables, such as drugs, and capital. Treatment of capital and sourcing prices for material costs (goods and services) for Australian hospitals was often problematic 
and varied dependent upon individual hospital funding arrangements $(25,27,28)$. In some instances the inclusion of capital was not considered appropriate for those public hospitals that do not own their own building assets, (25) was excluded from inclusion in analysis altogether, due to a lack of information available on capital assets $(24,29)$ or substituted for proxy measure such as number of beds $(28)$. Similarly, studies excluded material costs altogether (25) or utilised nominal or total expenditures (28). In the United Kingdom, changes and discrepancies in health data and collection also impacted on the ability to select appropriate input (and output data), making comparisons across years difficult (23).

The selection of output variables is particularly important. Ideally, a hospital's performance should be measured in terms of patient outcomes or other measures of quality of the care provided. Within Australia, however, there appears to be limited data available to directly measure patient outcomes or quality of care. As such, studies of Australian public hospitals have utilised so-called proxy measures of health performance that relate to hospital outputs, such as number of separations or occasions of service. Although such proxy measures are also utilised in studies of hospitals in the United Kingdom or Canada, some studies have utilised more direct measures of hospital performance, such as Potential Years of Life Lost (31) or median wait times (53). The United Kingdom productivity estimates, whilst not a true measure of efficiency, also apply quality adjustments, including factors such as measures of survival rate, estimated change in health outcomes following hospital treatment and mean life expectancy, change in inpatient waiting times (for elective, day case and non-elective activity and mental health care) and changes in outpatient waiting times. No Australian study utilised any such outputs relating to patient outcomes or quality of care and these studies provide a useful indication of how such approaches might be adopted in Australia, should such data become available.

In addition to the selection of input and output variables, many studies also investigated a number of other 'environmental factors' that may have contributed to identified inefficiencies. Commonly investigated characteristics included 'type' of hospital, e.g. teaching vs non-teaching hospitals, Trust vs non-Trust hospitals (UK) and geographic location. Such factors are highly relevant to Australia, where there is a significant variation in public hospital location and type. Of note, investigation of these factors was not restricted the type of analysis employed (e.g. DEA vs SFA).

Amongst the studies identified in this review, there was no clear consensus on a preferred analysis technique, whether this be DEA, SFA, Malmquist Indices or productivity indices (such as those employed by the United Kingdom). Within Australia SFA was employed most often, but this was not reflected elsewhere, with the majority of Canadian studies employing DEA and most recent United Kingdom studies employing a productivity index approach. With particular regard to DEA versus SFA, SFA when it was utilised was preferred for its ability to allow for measurement error, whilst DEA when it was employed for its greater flexibility, ability to handle multiple outputs and as a means to identify peers or role models by which benchmarks for performance can be established (29). A small number of studies employed a Malmquist Index approach for its ability to allow decomposition into efficiency and technology change (34) and the fact that it does not require input or output prices (47). What is clear from these studies is 
that the selection of analysis technique will be dependent upon the ultimate aims of the study and the availability of input and output data.

Perhaps the most striking observation from a reading of these identified efficiency and productivity analyses is the lack of engagement with the health system in the development and utilisation of these analyses. Those working within the health system are uniquely placed to advise on appropriate input and output variables that impact on efficiency and productivity in the sector, and most importantly, initiate appropriate action to drive improvements in efficiency and productivity. Yet there is little evidence of engagement with these stakeholders. Whilst there was some acknowledgement of the need for increased engagement with the health sector $(19,20)$ only one study actively consulted with health sector stakeholders in the development of their efficiency and productivity analysis (31). Moreover, no study reported any resultant uptake or impact by health system managers or policy makers. This lack of translation into the health system has previously been noted by Hollingsworth; of the close to 400 publications measuring economic efficiency in health care up to 2012 , there has been little take-up of this evidence by policy makers (63).

\section{Conclusion}

In the face of rising costs of health expenditure across many countries, (64) there is an urgent need to consider the efficiency and productivity of the health system and in particular the public hospital sector, which is one of the largest sources of health expenditure within Australia. Although there a large number of studies globally that consider efficiency and productivity of the health system, (65) within Australia and key comparator nations, the number of efficiency and analysis studies is small. The number of studies that demonstrate active engagement with the health sector in study development and translation to impact is even smaller. These studies uniformly grapple with the selection of inputs and outputs that can accurately reflect the production function of a given hospital and the selection of a fit for purpose analysis technique. There is considerable scope for the further development of efficiency and productivity analysis techniques that can adequately capture relevant production factors, allow for robust comparisons across hospitals and time periods and which meaningfully engage with the health sector to inform improvements in efficiency and productivity.

\section{Declarations}

\section{Ethics approval and consent to participate}

Not applicable

\section{Consent for publication}

Not applicable 


\section{Availability of data and materials}

Not applicable. Data sharing is not applicable to this article as no datasets were generated or analyzed during the current study.

\section{Competing interests}

The authors declare that they have no competing interests.

\section{Funding}

This research did not receive any specific grant from funding agencies in the public, commercial, or notfor-profit sectors.

\section{Author's contributions}

Bonnie Eklom: Conceptualization, Investigation, Writing - Original Draft Emily Callander: Writing Review \& Editing, Supervision

\section{Acknowledgements}

Not applicable

\section{References}

1. Schneider EC, Sarnak DO, Squires D, Shah A, Doty MM. Mirror, Mirror 2017: International comparison reflects flaws and opportunities for better U.S. health care. The Commonwealth Fund. 2017.

2. OECD. Health at a Glance 2017. Paris: OECD Publishing; 2017.

3. Department of Prime Minister and Cabinet. Reform of the federation white paper. Roles and responsibilities in health. Issues paper 3. Canberra: Australian Government; 2014.

4. National Commission of Audit. Towards responsible government. The report of the National Commission of Audit. Phase One. Canberra: Commonwealth of Australia; 2014.

5. Coelli TJ, Rao DSP, O'Donnell CJ, Battese GE. An introduction to efficiency and productivity analysis. 2 ed. United States of America: Springer US; 2005.

6. Farrell MJ. The Measurement of Productive Efficiency. Journal of the Royal Statistical Society Series A (General). 1957;120(3):253-90.

7. Auger CP. Information sources in grey literature. 4th ed. London; New Providence, N.J: Bowker-Saur; 1998. 
8. Godin K, Stapleton J, Kirkpatrick SI, Hanning RM, Leatherdale ST. Applying systematic review search methods to the grey literature: a case study examining guidelines for school-based breakfast programs in Canada. Systematic reviews. 2015;4:138-

9. Shamseer L, Moher D, Clarke M, Ghersi D, Liberati A, Petticrew M, et al. Preferred reporting items for systematic review and meta-analysis protocols (PRISMA-P) 2015: elaboration and explanation. BMJ : British Medical Journal. 2015;349.

10. Pan B, Hembrooke H, Joachims T, Lorigo L, Gay G, Granka L. In Google We Trust: Users' Decisions on Rank, Position, and Relevance. Journal of Computer-Mediated Communication. 2007;12(3):801-23.

11. Council of Australian Governments. National Health Reform Agreement. Canberra: Australian Government; 2011.

12. Australian Institute of Health and Welfare. About MyHospitals - MyHospitals overview | MyHospitals.gov.au: Australian Government; 2018https://www.myhospitals.gov.au/aboutmyhospitals/overview\#performance-indicator-reporting. Accessed 20 May 2018.

13. Ariste R, Yu K. Comparisons of hospital output in Canada: national and international perspectives. International Journal of Health Economics and Management. 2017;17(4):433-51.

14. Sharpe A, Bradley $\mathrm{C}$, Messinger $\mathrm{H}$. The measurement of output and productivity in the health care sector in Canada: An overview. Report prepared for the Canadian Medical Association. Centre for the Study of Living Standards; 2007.

15. Crémieux PY, Ouellette P, Rimbaud F, Vigeant $S$. Hospital cost flexibility in the presence of many outputs: A public-private comparison. Health Care Management Science. 2005;8(2):111-20.

16. Crémieux PY, Ouellette P. Omitted variable bias and hospital costs. Journal of Health Economics. 2001;20(2):271-82.

17. Preyra C, Pink G. Scale and scope efficiencies through hospital consolidations. Journal of Health Economics. 2006;25(6):1049-68.

18. Yu K. Measuring efficiency and cost-effectiveness in the health care sector. In: Yu K, editor. Essays on the theory and practice of index numbers: the making of macroeconomics data. Verkag: VDM; 2011.

19. Lavis JN. Dialogue summary. Measuring health system efficiency in Canada. McMaster Health Forum; Hamilton, Canada 2011.

20. Canadian Institute for Health Information. Developing a model for measuring the efficiency of the health system in Canada, updated October 2012.

21. United Kingdom Parliament. NHS: Productivity: Written Question - 224314. 2015. https://www.parliament.uk/business/publications/written-questions-answers-statements/writtenquestion/Commons/2015-02-11/224314/. Accessed 20 May 2018.

22. United Kingdom Office of National Statistics. Public service productivity estimates, healthcare: 2015. United Kingdom Office of National Statistics; 2018.

23. Castelli A, Chalkley M, Santana IR. Productivity of the English National Health Service : $2015 / 16$ update. CHE research paper 152. Centre for Health Economics, York University; 2018. 
24. Webster R, Kennedy S, Johnson L. Comparing techniques for measuring the efficiency and productivity of Australian private hospitals. Canberra: Australian Government; 1998.

25. Yong K, Harris A. Working Paper 92. Efficiency of hospitals in Victoria under casemix funding: A stochastic frontier approach. Melbourne: Centre for Health Program Evaluation; 1999.

26. Wang J, Zhao Z, Mahmood A. Relative efficiency, scale effect and scope effect of public hospitals: Evidence from Australia. IZA Discussion Paper Series. 2006;IZA DP No. 2520.

27. Gabbitas 0 , Jeffs $C$. Assessing productivity in the delivery of public hospital services in Australia: some experimental estimates. 30th Australian Health Economics Conference; 2-3 October 2008; Adelaide2008.

28. Productivity Commission. Public and Private Hospitals. Canberra: Australian Government; 2009.

29. Steering Committee for the Review of Commonwealth/State Service Provision. Data Envelopment Analysis: A technique for measuring the efficiency of government service delivery. Canberra: Australian Government; 1997.

30. Fixler T, Paradi JC, Yang X. A data envelopment analysis approach for measuring the efficiency of Canadian acute care hospitals. Health Services Management Research. 2014;27(3-4):57-69.

31. Allin $S$, Grignon $M$, Wang $L$. The determinants of efficiency in the Canadian health care system. Health Economics Policy and Law. 2016;11(1):39-65.

32. Chowdhury $\mathrm{H}$, Zelenyuk V. Performance of hospital services in Ontario: DEA with truncated regression approach. Omega (United Kingdom). 2016;63:111-22.

33. Asmild M, Hollingsworth $B$, Birch $S$. The scale of hospital production in different settings: one size does not fit all. Journal of Productivity Analysis. 2013;40(2):197-206.

34. Chowdhury H, Zelenyuk V, Laporte A, Wodchis W. Analysis of productivity, efficiency and technological changes in hospital services in Ontario: How does case-mix matter? International Journal of Production Economics. 2014;150:74-82.

35. Chowdhury $\mathrm{H}$, Wodchis W, Laporte A. Efficiency and technological change in health care services in Ontario: An application of Malmquist Productivity Index with bootstrapping. International Journal of Productivity and Performance Management. 2011;60(7):721-45.

36. Asmild M, Tam F. Estimating global frontier shifts and global Malmquist indices. Journal of Productivity Analysis. 2007;27(2):137-48.

37. Hollingsworth B, Parkin D. Efficiency and productivity change in the English National Health Service: Can data envelopment analysis provide a robust and useful measure? Journal of Health Services Research and Policy. 2003;8(4):230-6.

38. Bevan G, Karanikolos M, Exley J, Nolte E, Connolly S, Mays N. The four health systems of the United Kingdom: how do they compare? : London School of Hygiene \& Tropical Medicine; 2014.

39. Street A, Jacobs R. Relative performance evaluation of the English acute hospital sector. Applied Economics. 2002;34(9):1109-19. 
40. Dawson D, Goddard M, Street A. Improving performance in public hospitals: A role for comparative costs? Health Policy. 2001;57(3):235-48.

41. Scott A, Parkin D. Investigating hospital efficiency in the new NHS: The role of the translog cost function. Health Economics. 1995;4(6):467-78.

42. Street A. How much confidence should we place in efficiency estimates? Health Economics. 2003;12(11):895-907.

43. Castelli A, Street A, Verzulli R, Ward P. Examining variations in hospital productivity in the English NHS. The European Journal of Health Economics. 2015;16(3):243-54.

44. Castelli A, Laudicella M, Street A, Ward P. Getting out what we put in: productivity of the English National Health Service. Health Economics, Policy and Law. 2011;6(3):313-35.

45. Bojke C, Castelli A, Grašič K, Street A. Productivity Growth in the English National Health Service from 1998/1999 to 2013/2014. Health Economics. 2017;26(5):547-65.

46. Aragon MJA, Castelli A, Gaughan J. Hospital Trusts productivity in the English NHS: Uncovering possible drivers of productivity variations. PLoS One. 2017;12(8):e0182253.

47. Valdmanis V, Rosko M, Mancuso P, Tavakoli M, Farrar S. Measuring performance change in Scottish hospitals: a Malmquist and times-series approach. Health Services and Outcomes Research Methodology. 2017;17(2):113-26.

48. Productivity Commission. Public and private hospitals: Multivariate analysis. Canberra: Australian Government; 2010.

49. Braithwaite J, Westbrook MT, Hindle D, ledema RA, Black DA. Does restructuring hospitals result in greater efficiency - an empirical test using diachronic data. Health Services Management Research. 2006;19(1):1-12.

50. Gruca TS, Nath D. The technical efficiency of hospitals under a single payer system: The case of Ontario community hospitals. Health Care Management Science. 2001;4(2):91-101.

51. Bilodeau D, Crémieux P-Y, Jaumard B, Ouellette P, Vovor T. Measuring Hospital Performance in the Presence of Quasi-Fixed Inputs: An Analysis of Québec Hospitals. Journal of Productivity Analysis. 2004;21(2):183-99.

52. Bilodeau D, Crémieux P-Y, Ouellette P. Hospital performance in a noncompetitive environment. Applied Economics. 2009;41(4):459-68.

53. Abeney A, Yu K. Measuring the efficiency of the Canadian health care system. Canada: Lakehead University; 2015.

54. Allin S, Veillard J, Wang L, Grignon M. How can health system efficiency be improved in Canada? Healthcare Policy. 2015;11(1):33-45.

55. Canadian Institute for Health Information. Health system efficiency in Canada: Why does efficiency vary among regions? Canada; 2014.

56. Duckett SJ. Hospital payment arrangements to encourage efficiency: the case of Victoria, Australia. Health Policy. 1995;34(2):113-34. 
57. University of British Columbia Centre for Health Services and Policy Research. Current hospital funding in Canada. The limitations of global budgets.; 2014.

58. Canadian Institute for Health Information. Case Mix | CIHI. 2018. https://www.cihi.ca/en/submitdata-and-view-standards/methodologies-and-decision-support-tools/case-mix. Accessed 30 May 2020.

59. The Commonwealth Fund. England : International Health Care System Profiles. 2018. https://international.commonwealthfund.org/countries/england. Accessed 20 June 2020.

60. Allin S, Grignon M, Wang L. The determinants of efficiency in the Canadian health care system. Health Economics, Policy and Law. 2014;11(1):39-65.

61. Evans RG, Walker HD. Information theory and the analysis of hospital cost structure. The Canadian Journal of Economics. 1972;5(3):398-418.

62. Australian Medical Research Advisory Board. Medical Research Future Fund: Australian medical research and innovation strategy 2016-2021. Canberra: Australian Government; 2016.

63. Hollingsworth B. Revolution, evolution, or status quo? Guidelines for efficiency measurement in health care. Journal of Productivity Analysis. 2012;37(1):1-5.

64. Marino A, Morgan D, Lorenzoni L, James C. Future trends in health care expenditure. 2017.

65 . Hollingsworth $B$. The measurement of efficiency and productivity of health care delivery. Health Economics. 2008;17(10):1107-28.

\section{Figures}




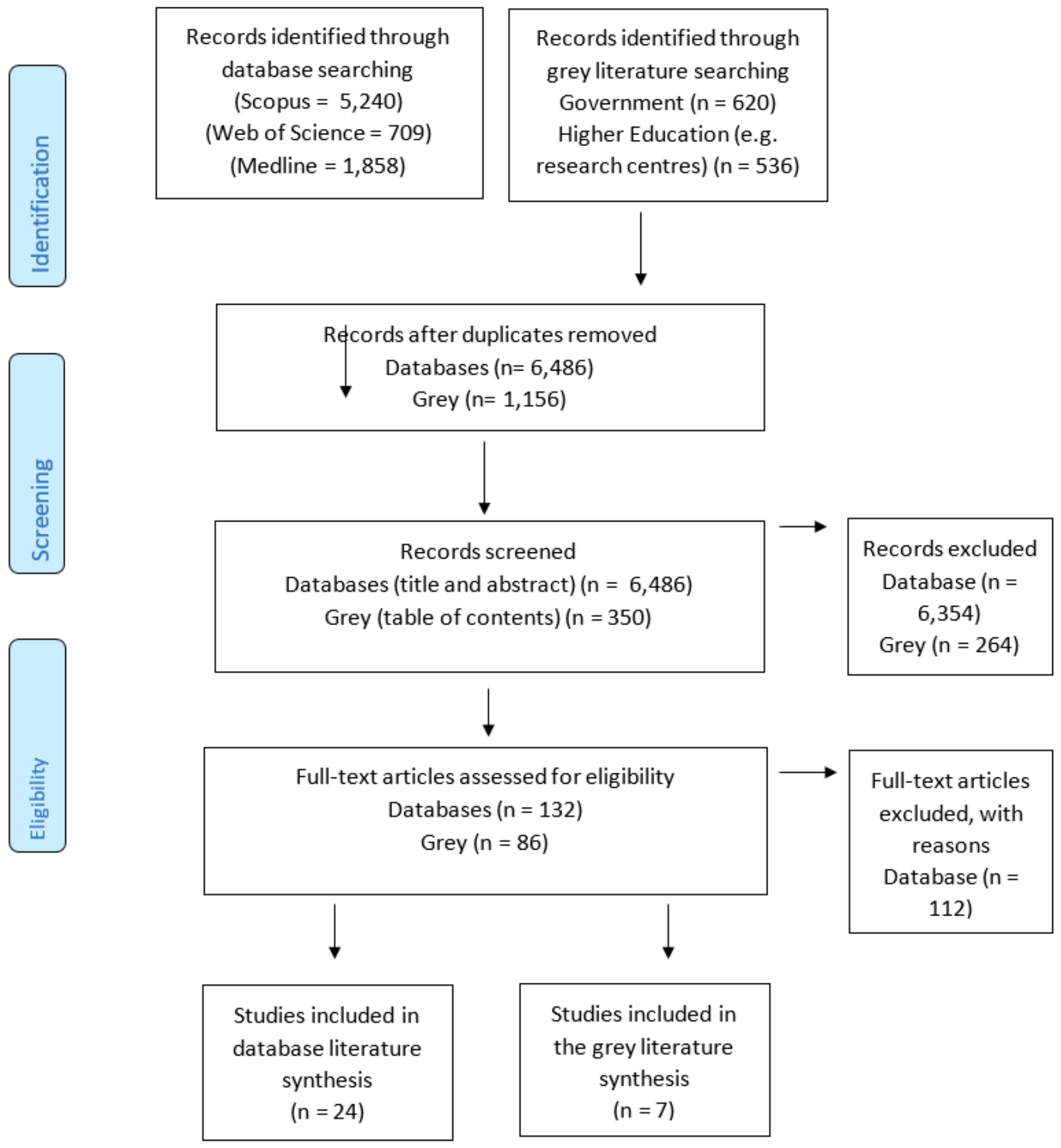

Figure 1

PRISMA Flow Diagram

\section{Supplementary Files}

This is a list of supplementary files associated with this preprint. Click to download. 
- AdditionalFile1PRISMA2009checklistrevised07122020.doc 